\title{
Improving the websites user experience (UX) through the human-centered design approach (An analytical study targeting Universities websites in Egypt)
}

\author{
Ta. Nada Hosseini ${ }^{1)}$, Prof. Tamer Abdellatif ${ }^{2)}$,Dr. Rania Farouk A.A. Nakhil ${ }^{\text {3) }}$ \\ 1) Teaching Assistant at AOU University/ Masters student \\ 2) Professor at Advertising Dep., Faculty of Applied Arts, Helwan University \\ 2) Professor at Advertising Dep., Faculty of Applied Arts, Helwan University
}

Submit Date: 2020-05-09 18:32:23

\begin{tabular}{l|l|l|l|} 
Revise Date:2021-04-05 10:39:33 Accept Date: 2021-04-10 23:05:37 & Act
\end{tabular}

DOI: 10.21608/jdsaa.2021.29802.1029

KEYWORDS:

User experience, human centered design, satisfaction, higher educational system.

\begin{abstract}
:
User experience (UX) in general aims to improve the way human interact with a product, brand or service to achieve higher levels of satisfaction. Through his behavior, emotions and attitudes we can conclude the effective strategy to build a positive relationship between him and the brand.

Human centered design as a term considered one of the new creative approaches to building a deep empathy with people in different creative industries. It is about gaining a deeper understanding of consumer insights.

Designing strong User experience depends on the right mixture of elements of design; shapes, colors, navigation, content and sounds to evoke different feelings or emotions such as welcoming, exciting or curiosity to reach enough levels of satisfaction. Understanding people and how they interact is crucial, especially in designing a new website.

Research problem: Educational websites are considered one of the most effective channels in building trust, engagement and satisfaction towards the universities. This makes Improving website user Experience very important to build a strong university's brand image in general and reach higher levels of student's satisfaction. The research suggests that depending on Human centered design approach could improve UX to reach the needed satisfaction levels. Purpose This research investigates the role of human centered design in helping user experience to achieve higher levels of satisfaction towards specific websites.

Methodology: an analytical study is adopted targeting some Educational websites in Egypt to explore how design disciplines can improve user experience considering human centered design approach. Measuring users' satisfaction levels toward specific Educational websites and the effect of HCD in increasing these levels. Findings: Human centered design improves Educational websites UX and able to achieve higher levels of user's satisfaction through a deep understanding of user insights and the reflection of this understanding on designing websites.
\end{abstract}




\section{INTRODUCTION:}

The internet is completely changing the old-style way that organizations cooperate with public. For organizations, the web offers access to a huge audience and increases operational productivity. Web sites are becoming basic components of an organization's survival in the globalized competition. The web site represents an organization, communicating an organization's culture, values, and vision. H. Turan 2012) believes that web site acts as a delivery means for services that simplify various tasks a stakeholder needs to complete. The website also helps as a platform through which an organization can interact with its stakeholders. Icons 8 (2019) considered that competition becomes much stronger, the desirability of the websites demonstrating educational institutions is speedily becoming one of the factors that students take into account when selecting their path. In today's academic societies, universities have recognizable the importance of having websites to be able to benefit from suitable academic communications. Furthermore, students' satisfaction from a university website displays to some extent college's web achievement. Awan et al. (2016) added that usability of websites measured by its user adaptive level, screen understanding level, satisfaction and learnability. The above- mentioned factors affect availability of a website design, user adaptation and show of contents with ease of use and navigation. Zalewski stated a great user experience on your site approves that your visitors can find all they're looking for with ease and speed. It's up to you to create a content-rich, meaningfully designed site that keeps your customers and partners engaged and resuming for more. Harte et al (2017) describe Design processes for example human-centered, which contain the end user through the product progress and testing process, can be necessary in confirming that the product meets the needs and abilities of the user, especially in terms of security and user experience.

Moorhead (2017) added that Human-centered design is a creative method to communicating systems development that wishes to make systems usable and valuable by concentrating on the users, designing around their requirements and desires at all stages, and by applying human factors/ergonomics, usability knowledge, and techniques. This approach improves effectiveness and productivity, develops human well-being, user satisfaction, availability and sustainability; and responds possible adverse effects of use on human health, security and performance.

P. Magee (2017) defined HCD its about turning understanding concepts into certain product requirements Empathy-based thoughts such as user's attitudes, feelings, frustrations take a fundamental stage in user-centered design. Babich (2019) stated Product designers should be able to turn empathy-based perceptions into organized requirements such as the user's targets and interaction lifestyles something that a whole team be able to use to make a product.

\section{2- Human centered design approach}

Now a days Human centered design plays an important role to identify new chances for companies and institution by expressing new markets to diversify for current products. When you're connected straight to your users, you can follow their needs that provide user a sense of being understood, which can increase user's loyalty Hence, we will review the views of some researchers and the extent of their definition of an HCD approach.

IDEO (2019) stated that human centered design (HCD) "sits at the connection of understanding and creativity." It is a design and management framework that improves solutions to problems by connecting the human perspective in all phases of the problem-solving process. Babich (2018) described Human centered design it is a term product creator which used to describe a design process for people. Forsey (also agreed that HCD its method to problem-solving that demands to put your consumer's needs first when following an issue. To use human-centered design for your development, you must recognize your consumer deeply, know with a valid problem they face, and come up with solutions they'd hold. Most of them revolve nearby that HCD means creating products to solve your consumer's struggles and help them for easier and better live Yalanska (2018) said that human-centered design is process of producing things based deeply on general natural characteristics of human thinking and perception.

From all of these definitions, it is clear that the human-centered design puts the user first and begins to study all his needs and how to achieve this in the final 
product that he provides to him, whether by strengthening the user's experience or by mixing different design elements to make it accomplish the usability From the product or website to satisfy the user.

\subsection{HCD as an approach to enhance user experience} Asad (2018) said that HCD revolves around the approach to UI/UX designing that is made to increase the usability and user experience of a certain website or app. A website can only be valuable to the users if they do not discover any hurdles in editing each feature, content, and links then it suggests the sign of a stable and precious user interface.Vic.gov. au (2019) described that the best way to study how to handle UX research is to understand the different types of research methods available, and then dive in and do it. The information classified here frameworks a human-centered design development to keep on and suggestions some of resources to aid you to do that. Philips (2019) said that when well done, a human-centered approach drives the foundation of products that resonate more extremely with an audience, finally powerful engagement and progress. as proof of we need to look no addition than the recent achievement of design-driven companies like Warby Parker, Apple, Fab, and Airbnb. We've also newly seen big-players similar to Google, eBay and LinkedIn invest in the design of more included and developed user experiences.

\subsection{The Main Phases of Human-Centered Design}

Desmond (2018) descried the steps of how to accomplish effective human-centered design:

- Notice and brainstorm: Start by making expectations about your audience and sketch questions to both check or expose your views.

- User opinion: Now you have your questions written, it's time to ask your questions to real customers. If you have several diverse audiences, go speaking with them at least person from each section.

- Ideation: by have your user response, drawing the board and consider how you can utilize their opinions in your website design.

- Implementation: Implement your strategy of action and make your human-centered website design arise to reality.
- Analyze: After a few months, take a look at your Analytics and understand that your method to your design worked in your favor or wrong. If you feeling like it could expand, go again to your users and ask for their opinion towards the design.

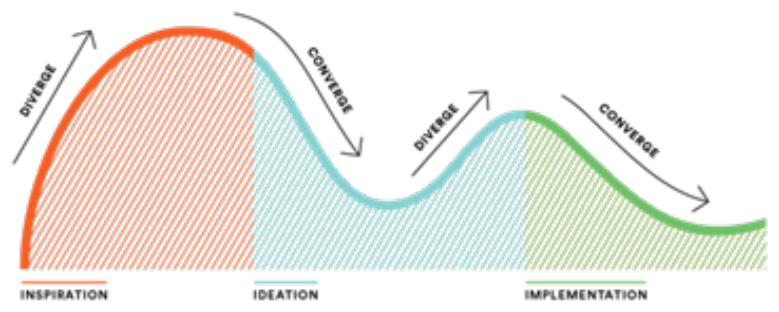

Fig (1): Phases of Human-Centered Design (ideo.org, 2018)

\subsection{Principles of Human-Centered Design}

Z.Maryna (2017) confirmed that "Human-centered design" does not basically force you to believe the desires and requirements of product users first. The question is how can you satisfy individuals desires in both functional and psychologically meaningful methods. There are 3 common principles of human-centered design:

- Collaboration: Great minds produce great concepts when they work together.

- Empathy: You can't form a product for people if you don't understand their desires deeply.

- Experimentation: It's through conversations only, investigates and learning that a well product will be born.

\subsection{Website design and human centered design}

510.global (2019) described using a human-centered approach to design and development has substantial social and economic benefits for people affected, aid workers and inter-sectorial cooperation. Highly usable systems and products tend to be more successful both technically (feasibility) and inter-sectoral (viability) when all users can understand and use products without additional assistance. Classifications considered HCD approaches increase value, for example, by:

- Improved user experience decreasing uneasiness and worry.

- With a wider range of capabilities, we can in- 
crease usability for people, therefore enhancing user-friendliness.

- Improved efficiency of all consumers and the operating efficiency of institutes.

- Informal to use and recognize, therefore decreasing coaching and reduce costs.

- Contribute regarding scalability purposes

\subsection{Human-Centered Design process to create ef- fective website experience}

League (2019) stated that we can make an optimal user website experience through sevens stages:

1. Make identification with user personas

2. Assess what user personas need from your website

3. Map their trip through the website to key renovation

4. Recognize problems in their track

5. Brainstorm clarifications

6. Arrange clarifications

7. Make a roadmap to improvement

\section{3- User Experience}

Nakhil (2019) stated that UX is the base of the upcoming engagement. So, improving the user experience is the new approach, through personalization and straight communication. The user wants to feel valuable and respected. Pines (2018) descried Users need to have a touching linking to the experience of using your website. Grass (2019) showed that if you are simply creating an interface and not an experience, you have limited chance of gaining the following you need to make your product a success.

\section{1- Principles of User Experience Design}

Memon (2019) said that UX design is a creative field that greetings new opinions from new specialists, however there are about foundational UX design principles every new designer should recognize it.

\section{1- Visual hierarchy}

hierarchy means to how content is prepared throughout the application or website. The top level of the hierarchy is frequently a main direction menu that contains the main units.

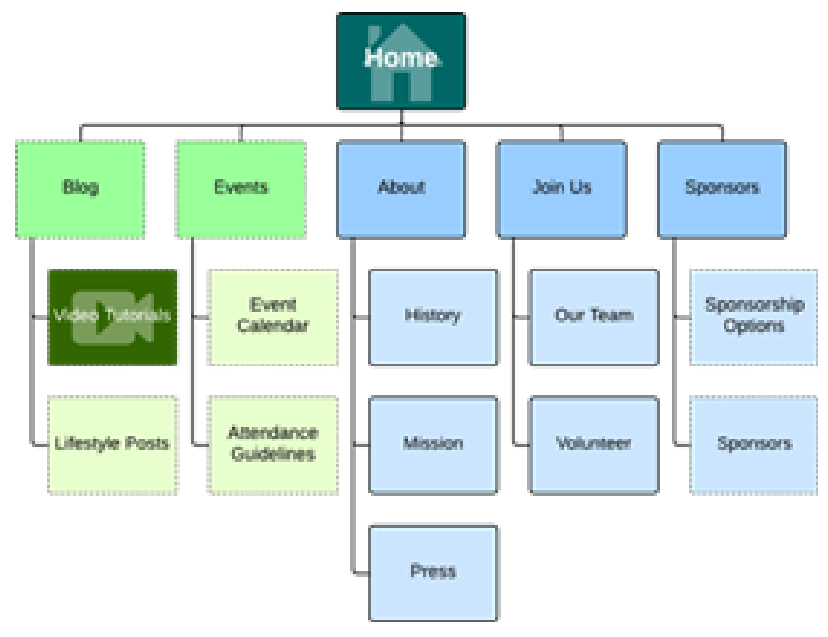

Fig (2): hierarchy in user experience Memnon (2019)

\section{2- Consistency}

Users suppose that products have to share some connections with other products they use regularly. which makes it easy for them to become well-known with the new product without any extra learning fees.

\section{3- Confirmation}

This type of confirmation offers opportunity to users which inverse an unplanned action or to reconsideration something they not certain of it.

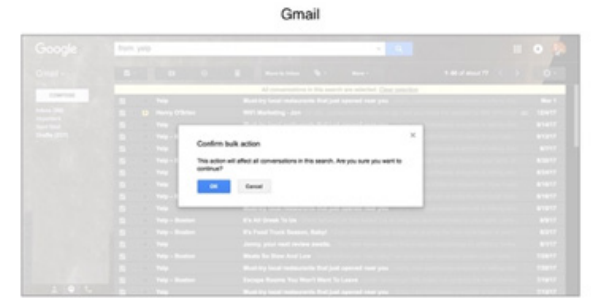

Fig (3): confirmation in user experience Grass (2019)

\section{4- User Control}

Users have a good experience you can give them more control when they are use the product and they will be doing well according their knowledge.

\section{5- Accessibility}

Accessibility means that designing products to be easy for users with incapacities to use. Meanwhile we design products for people, it's necessary that our products can be used excepted consumers. 


\subsection{User Experience \& Usability to achieve satisfac- tion}

Harte etal (2017) defined usability as "it's the extent to which a user can use a product to complete particular goals with effectiveness, efficiency and satisfaction in a stated framework" Soegaard (2020) described the difference between usability and the whole part of user experience. Core areas of the user experience include Usability which measure he user's skill to reach website, use it easily, and complete the required task the good ux comes when the user can arrange an emotional bond with the product or website. That means moving beyond usable and useful and on to evolving content that produces that promise. From that points of views, the usability is an important design Naturally. However, we need to consider usability together with these additional concerns to create a great user experience. User experience comes as much from interactive design, content, etc. as it apart of usability.

\section{Methodology:}

A quantitative study was conducted, through an online survey, targeting 170 Egyptian students registered in four different Egyptian well known and well-established universities (non-dual degree nor international) according to the classification of the Egypt scientific committee These universities have been chosen for the availability of learning management system in them and also there is a diversity in the educational level in them so that the measurement is accurate enough to measure the importance of improving their websites.

Governmental university websites do not have a way for students to interact with the university directly, as learning management system that exists in private universities

The students are chosen according their specifications, the common faculty in the 4 university was Business Administration with different minors; (accounting, marketing, management) chosen to reduce differences between students regarding the type of education.

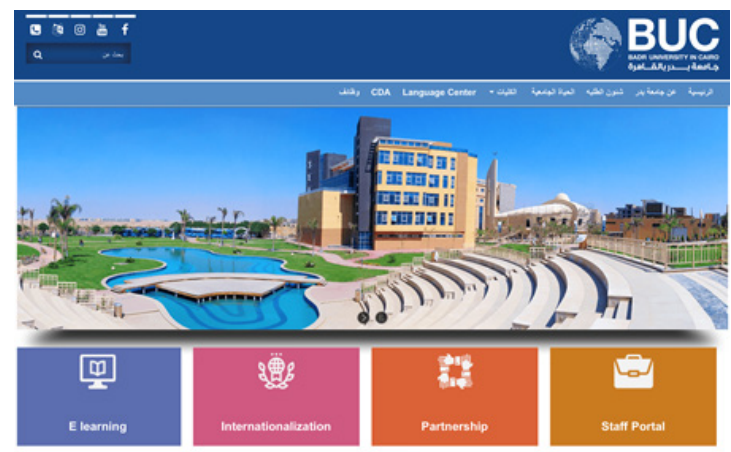

- University: BUC (Badr University in Cairo)

- Location: in Ismailia Road Ahmed Orabi District, Cairo - Egypt

- Home page in website contain energetic colors and different sections but there are a lack of important data.

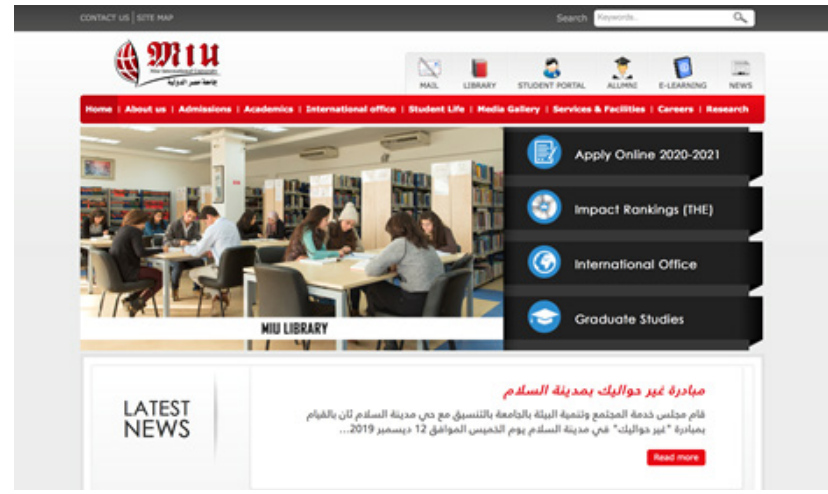

- University: MIU (Misr International University)

- Location: in Badr city, Cairo - Egypt

- Home page: in website very organized sections contain section for student support and section for external user's

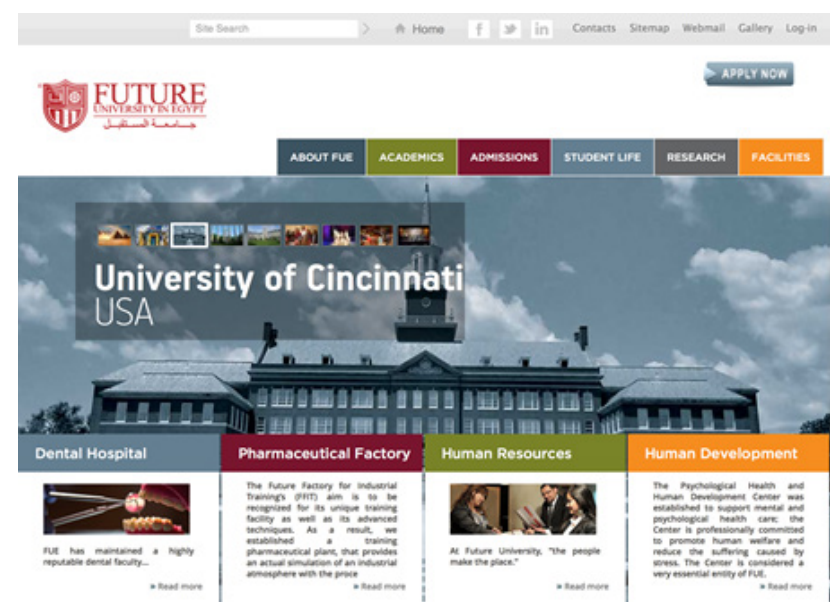

- University: FUE (future university in Egypt)

- Location: in New Cairo, Cairo - Egypt

- Home page: in website contain luxuries image which reflect efficacy. Home page cover all needs of website users

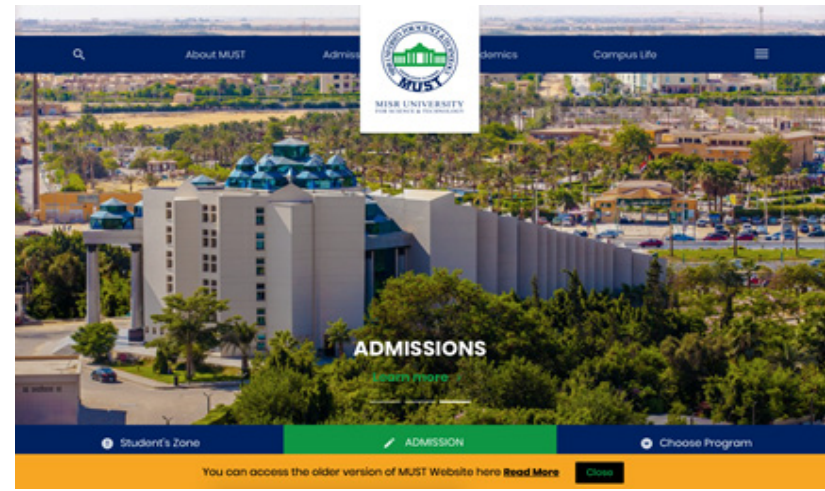


- University: MUST (Misr University for Science and technology)

- Location: located in 6 October city, Cairo Egypt

- Home page: represent unfamiliar layout but shows university brand image by using logo colors

The sample included only $2 \mathrm{nd}, 3$ th, 4 th year in the university, the first level (freshmen) was excluded to ensure the ability of students to deal with the educational system in general and to be certain about the student experience.

The study has been done through two stages: the first one aimed to evaluate the student's university website and the second stage aimed to evaluate the other website (each student chose the website he wanted by clicking the logo button) without any intrusion from the observant.
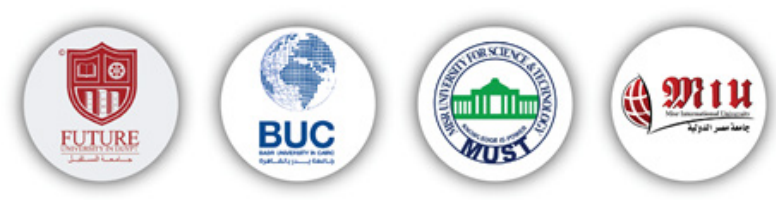

Fig (4): University highlighted by different color and he choose another one by clicking the logo button

Both stages aimed to measure the satisfaction rate of the student towards his university website considering reducing the effect of his emotions towards his own university (positively or negativity)

\section{Measuring student satisfaction}

According to Phongphaew (2018) who evaluated LMS usability, by measuring five features of learnability, efficiency, memorability, effectiveness, and satisfaction were measured. These usability attributes were described as follows: Table (1) phongphaew five features of measuring usability (2018)

\begin{tabular}{|c|l|}
\hline Learnability & $\begin{array}{l}\text { The time for each task completed } \\
\text { in the first time of use, when it } \\
\text { takes less time that mean how } \\
\text { easier it will be to use }\end{array}$ \\
\hline Efficiency & $\begin{array}{l}\text { Short time of completion familiar } \\
\text { task to the system indicator of } \\
\text { efficiency }\end{array}$ \\
\hline Memorability & $\begin{array}{l}\text { Less time to do a task after } \\
\text { leaving the site for a week means } \\
\text { a good memorability }\end{array}$ \\
\hline Effectiveness & $\begin{array}{l}\text { (TSR) The task success: ratio is } \\
\text { the product of completion ratio } \\
\text { multiplies with accuracy ratio. } \\
\text { Completion ratio is the actual } \\
\text { number of page change divided } \\
\text { by predictable number of page } \\
\text { change. Accuracy ratio is the } \\
\text { actual number of click divided by } \\
\text { predictable number of click }\end{array}$ \\
\hline Satisfaction & $\begin{array}{l}\text { After questionnaire at the end of } \\
\text { each mission and the Post-Study } \\
\text { System Usability Questionnaire } \\
\text { at the end of each phase }\end{array}$ \\
\hline
\end{tabular}

\section{Hypothesis:}

H1: Increasing satisfaction rate is directly proportional with improving website user experience

H2: Usability could be an effective tool in improving user experience if "HCD" is considered as a strategic approach.

- The students were asked to fill their own personal data as an (option) we excluded 2 out of stage one who didn't fill the date to be equal to the 2 nd stage.

- Number of students filled the whole survey in stage one was: 162 student, Number of students filled the whole questionnaire in stage two was:160 student 
Table (2)

\begin{tabular}{|c|c|c|c|}
\hline University & females & males & Total \\
\hline BUC & 25 & 22 & 47 \\
\hline MIU & 19 & 18 & 37 \\
\hline FUE & 27 & 31 & 58 \\
\hline MUST & 18 & 20 & 38 \\
\hline
\end{tabular}

Table (3)

\begin{tabular}{|c|c|c|}
\hline & First stage & second stage \\
\hline Learnability & 130 & 150 \\
\hline Efficiency & 125 & 147 \\
\hline Memorability & 127 & 152 \\
\hline Effectiveness & 131 & 149 \\
\hline
\end{tabular}

\section{Findings and Discussion:}

Study showed $94 \%$ of the student are able to remember the BUC website; style and elements. Energetic colors might be the main reason, which agreed with most of color research and its effect on memorability, in addition to the color scheme and how could it affect the target group regarding their characteristics. While only $72 \%$ found it effective, they consider the lack of important data they need is the main reason, However, MIU effectiveness reached 93\% maybe because of its organized enough and helps even external users to find what they search for. On the other hand, FUE website learnability rate was $90 \%$, student found that its home page covers all data they need. But Must rate be just $70 \%$ because they found it not familiar enough while its memorability was $89 \%$ maybe because they considered university identity consistency through the whole website.

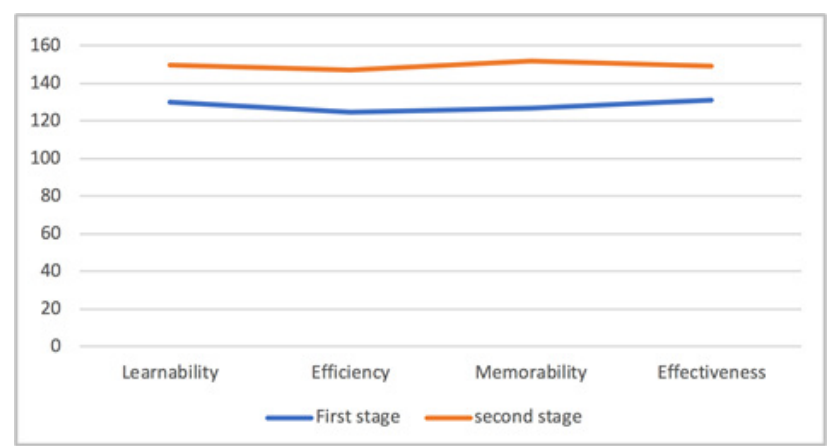

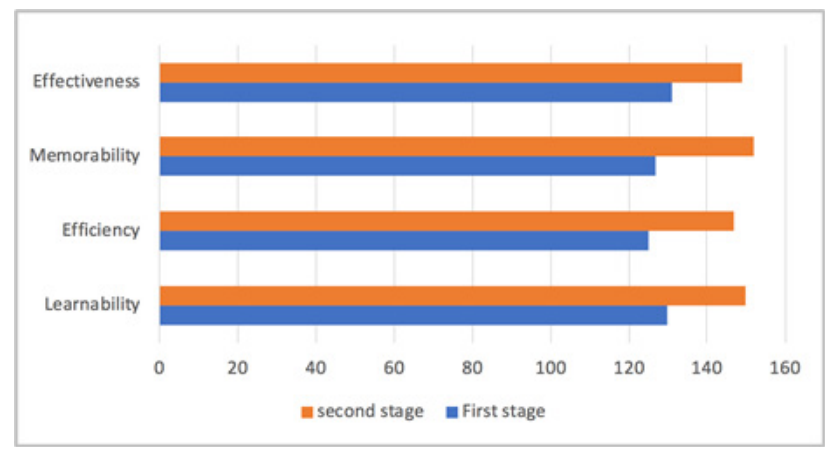

Fig (5) \& (6) shows the results of the study

Accordingly, we can confirm that there is no gender impact on satisfaction rates between students. Another noticeable observation regarding the psychological effect of the student's university in comparison with his likeability toward the different one. (More studies are recommended to fill this gap, because this issue arises the lack of loyalty towards their university). To improve the websites user experience visual hierarchy should be enhanced through browsing website, to make user's eye follows his path to reach important topics in a predictable way. A recognizable navigation layout could increase the user comfortability through focusing on familiarity and efficiency. The website should present honest and suitable information and data to cover the users' needs to increase website credibility.

1. User experience has an impactful role in increasing the satisfaction rate in websites

2. Usability that depends on HCD which done according to understand the needs and characteristics of website users has a positive effect on improving user experience

\section{Conclusion:}

This paper is an attempt to discuss how to improving websites user experience through human centered design approach, After the current innovation in the way of communication between institutions and organizations with expected users, the percentage of website has increased, which reflects the extent of its development and highest engagement between them and users. It was important to study the user in a way that meets his needs to reach satisfaction towards institutions or the company he deals with.

Improving websites user experience become more important to make users fell being understood well from that point new approaches like human centered design appears which aims to solve users struggles by deeply 
focus in his needs and how it changed through time that's discovers new solutions to meet user expectations. When user needs are ignored, nobody would prefer opening websites so that we need to enhance website usability through feel the gap between user's requirement and what he found in his round throughout website.

University websites should take action to improve their image towards student by apply principles of HCD Which improve Educational websites UX and able to achieve higher levels of user's satisfaction through a deep understanding of user insights and the reflection of this understanding on designing websites.

\section{References:}

1. Asad Nida "Human-Centered Design: 9 Examples To Justify Why It Matters" 2018 available online https:// www.wowmakers.com/blog/9-human-centered-design-examples/

2. Awan Sarfraz, A TECHNIQUE TO INCREASE THE USABILITY OF E-LEARNING WEBSITES, ResearchGate, 2016 Available online https://www.researchgate.net/publication/305479002

3. Babich Nick "Top 4 Principles of Human-Centered Design" https://uxplanet.org/top-4-principles-of-humancentered-design-5e02751e65b1 / SEP 2018

4. Babich Nick, User Centered Design Principles \& Methods, adobe xd, oct 2019 Available online https://xd.adobe.com/ideas/principles/human-computer-interaction/ user-centered-design/

5. Desmond Brooke "How to utilize human center design for your website" Dec,2018 Available online https:// www.greenmellenmedia.com/how-to-utilize-humancentered-design-for-your-website/

6. Forsey Caroline "Using Human-Centered Design to Create Better Products" https://blog.hubspot.com/marketing/human-centered-design

7. Grass, jonny "the 5 key of user experience principles" June 2019 available online https://careerfoundry.com/ en/blog/ux-design/5-key-principles-for-new-ux-designers/

8. H. Turan Aykut, ASSESSING THE USABILITY OF UNIVERSITY WEBSITES, TOJET , July 2012

9. Harte Richard, etal "A Human-Centered Design Methodology to Enhance the Usability, Human Factors, and User Experience of Connected Health Systems "2017

10. Icons $8 / \mathrm{https}: / /$ icons $8 . c o m / \mathrm{https} / / /$ icons $8 . c o m /$ articles/ ux-design-educational-websites/ may 2019

11. IDEO HUMAN CENTERED DESIGN .ideo.org https://www.ideo.org/work https://www.510.global/human-centered-design/ April 2019

12. League mindy "7 Steps to Website Transformation with Human-Centered Design" April 2017 Available online https://www.prometsource.com/blog/7-steps-web- site-transformation-human-centered-design

13. Memon, Masooma "Important UX Design Principles for Newcomers" Feb 2019 available online https:// www.springboard.com/blog/ux-design-principles/

14. Moorhead Anne " A Human-Centered Design Methodology to Enhance the Usability, Human Factors, and User Experience of Connected Health Systems: A Three-Phase Methodology" Mar 16, 2017 Available online https://www.ncbi.nlm.nih.gov/pmc/articles/ PMC5374275/

15. Nakhi, Rania "Meaningful storytelling as a brand engagement approach" 2019 Published in International Journal of Innovation and Applied arts

16. P. Magee James, How Can Human-Centered Design Be Used to Implement A Teacher-Designed, Standards-Based Curriculum? August, 2017

17. Philips Miklos" The Importance of Human-centered Design in Product Design" 2019 available online https:// www.toptal.com/designers/ux/human-centered-design

18. Phongphaew,Nattaporn " Usability Evaluation on Learning Management System” July 2018 published in researchgate available online https://www.researchgate. net/publication/318157972_Usability_Evaluation_on Learning_Management_System

19. Pines, Ben "7 UX Principles for Creating a Great Website " may 2018 available online https://www.webdesignerdepot.com/author/Ben-Pines/

20. Soegaard, Mads "Usability: A part of the User Experience" Jan 2020 available online https://www. interaction-design.org/literature/article/usability-a-part-of-the-user-experience

21. Vic.gov.au "Research user experience (UX) - Digital Standards" www.vic.gov.au available online https:// www.vic.gov.au/research-user-experience-ux DEC 2019

22. Yalanska Marina "Human-Centered Design VS User-Centered Design" https://tubikstudio.com/faq-design-platform-human-centered-vs-user-centered-arethe-terms-different/ / Dec 2018

23. Z.Maryna "A Guide to Human-Centered Design Methodology and Process" July 2017 available online https://rubygarage.org/blog/human-centered-design\#article_title_0

24. Zalewski justin " 6 Simple Steps to Improve User Experience" without Available online https://www.convinceandconvert.com/digital-marketing/improve-user-experience/ (accessed Jan 20, 2020

\section{Websites:}

25. 510.global "human centered design" April 2019 Available online https://www.510.global/human-centered-design/

26. https://www.hexwhale.com/improve-user-experience-website/

27. https://www.nngroup.com/articles/university-sites/

28. https://www.webdesignerdepot.com/author/Ben-Pines/ 